\title{
Conditions of Cervical Vestibular Evoked Myogenic Potentials Test to Minimize Interaural Variation
}

\author{
Sang Hyun Park, Woo Sung Na, Hong Geun Kim, Bong Jik Kim, and Jae Yun Jung \\ Department of Otorhinolaryngology-Head \& Neck Surgery, Dankook University College of Medicine, Cheonan, Korea
}

\section{양이간의 비대칭성을 최소화하기 위한 경부 전정유발 근전위 검사 조건}

박상현 · 나우성 · 김홍근 · 김봉직 · 정재윤

단국대학교 의과대학 이비인후-두경부외과학교실

\author{
Received April 1,2015 \\ Revised June 2, 2015 \\ Accepted June 2, 2015 \\ Address for correspondence \\ Jae Yun Jung, MD, PhD \\ Department of Otorhinolaryngology- \\ Head \& Neck Surgery, \\ Dankook University \\ College of Medicine, \\ 201 Manghyang-ro, Dongnam-gu, \\ Cheonan 31116, Korea \\ Tel $+82-41-550-3973$ \\ Fax $+82-41-556-1090$ \\ E-mail jjkingy2k@gmail.com
}

Background and Objectives Cervical vestibular evoked myogenic potentials (cVEMP) test has been widely used to assess the function of the saccule and inferior vestibular nerve. Electrode location and stimulating sound are important factors which might affect the test results. Today those parameters are usually selected to maximize the waveform response. In this study, we tried to find the optimal condition to minimize the range of normal value of cVEMP.

Subjects and Method Thirteen normal subjects (26 ears) were included. We placed electrodes at five different locations over the sternocleidomastoid muscle (SCM) and used four different stimulation sounds. Variances of parameters, including interpeak amplitude, interaural difference (IAD) and normal value were analyzed and compared.

Results When using the classical condition (mid point of SCM and $500 \mathrm{~Hz}$ ) without rectification, IAD ratio was $20.8 \pm 14.2 \%$ and the range of normal value was $39 \%$. When we used 2000 $\mathrm{Hz}$ tone burst sound at the classical electrodes site, IAD ratio and normal value were minimized, resulting in $18.7 \pm 14.3 \%$ and $31 \%$ respectively. After the rectification, when using the classical condition, IAD ratio was $26.4 \pm 22.3 \%$ and the range of normal value was $49 \%$. The minimum IAD ratio was measured as $17.4 \pm 13.7 \%$ when we used click sound at SCM at the level of mandibular angle. And the minimum normal value of $32 \%$ was measured when we used $1000 \mathrm{~Hz}$ tone burst sound at SCM at the level of mandibular angle.

Conclusion Although the condition was not optimal for maximizing the interpeak amplitude, we could alternatively use the condition to minimize the normal value.

Korean J Otorhinolaryngol-Head Neck Surg 2015;58(9):609-14

Key Words Cervical vestibular evoked myogenic potentials · Interaural difference · Normal value.
서 론

강한 소리 자극 후에 경부 근육에서 근전위 반응이 나타난 다는 사실이 알려지고 반응의 부위 및 경로 임상적 의미 등 에 대해 연구가 되었고 그 결과 전정기관 중 구형낭에서 하전 정신경과 전정척수로를 통해 흥쇄유돌근으로 가는 전정척수 반사로 추정되며 이를 경부 전정유발 근전위(cervical vestibular evoked myogenic potentials, cVEMP)라고 명명하였다.
전정기능을 평가하는 검사 중에서 온도안진검사와 회전의 자검사는 주로 수평반고리관의 기능을 평가하며 환자에게 불쾌감을 줄 수 있는 단점이 있다. 그러나 cVEMP는 구형낭 을 포함한 일측의 전정척수반사로의 기능을 평가할 수 있고, 다른 전정기능검사에 비해 비교적 쉽게 측정할 수 있다는 장 점이 있다. ${ }^{2)}$ 그러나 양이의 p13과 n23 사이의 진폭(interpeak amplitude)을 비교한 양이간 진폭 차이비(interaural amplitude difference ratio, IAD ratio)를 이용한 cVEMP의 정상 상한치 
는 다른 검사들에 비해 비교적 높아 임상적인 한계가 있다.

적절한 자극음의 종류와 주파수 그리고 전극의 위치를 선 택하는 연구들을 통하여 $500 \mathrm{~Hz}$ short tone burst(STB), 흥쇄 유돌근의 중간 부위에서 $\mathrm{p} 13, \mathrm{n} 23$ 을 통해 구해진 interpeak amplitude가 높은 수치를 보인다고 알려져 있다. ${ }^{3,4)}$ 그러나 이 러한 조건은 실제 임상적인 의미를 가진 IAD ratio에 최적화 된 조건은 아니기에 본 연구에서는 IAD ratio 영향을 줄 수 있는 조건들 중에서 자극음 종류, 주파수, 표면 전극의 위치 를 달리하여 IAD ratio가 가장 작은 자극음과 전극의 위치를 확인하고 $\mathrm{cVEMP}$ 의 정상 상한치(normal value)를 구하여 $\mathrm{cVEMP}$ 의 민감도를 높이고자 하였다.

\section{대상 및 방법}

두부외상, 난청, 어지럼증의 병력이 없는 정상 고막을 가진 건강한 22 38세의 정상인 13명(남 7명, 여 6명)을 대상으로

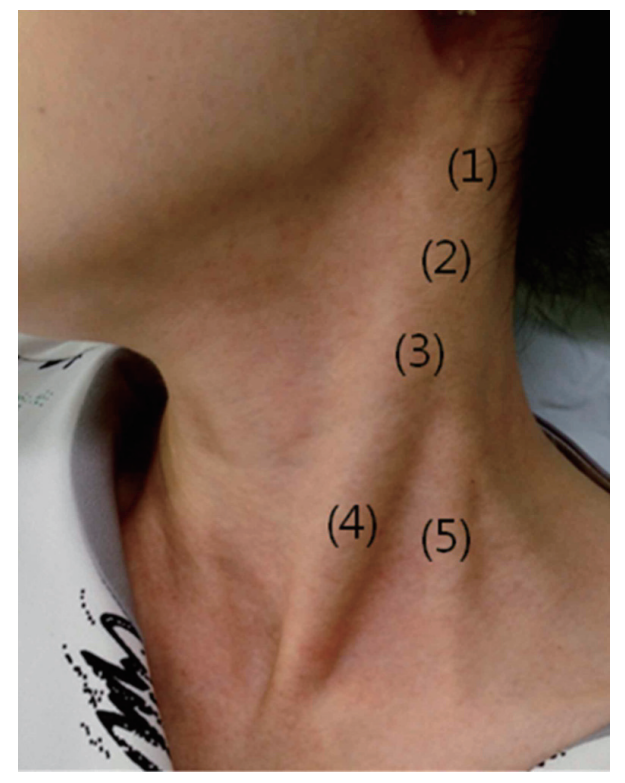

Fig. 1. Electrode locations were: (1) the upper part of the SCM at the level of mandibular angle, (2) the center between site (1) and site (3), (3) the classical electrode site, (4) the center of sternum division of the SCM, (5) the center of clavicle division of the SCM. SCM: sternocleidomastoeid.
검사를 시행하였다. 모든 연구 대상자는 연구 시행 전 동의서 를 작성하였으며, 본 연구는 헬싱키 선언을 준수하였다. 참고 전극은 쇄골의 중앙 전연에, 접지 전극은 이마 정중앙에 붙이 고 표면 전극은 기존 검사시 전극 부착 부위인 흥쇄유돌근의 중앙부위(site 3), 유양돌기(site 1), 기존 부착 부위와 유양돌 기의 중앙부위(site 2), 흉쇄유돌근 흥골분지의 중앙부위(site 4), 흥쇄유돌근 쇄골분지의 중앙부위(site 5)에 부착하였다(Fig. 1). $500 \mathrm{~Hz}, 1000 \mathrm{~Hz}, 2000 \mathrm{~Hz}$ 의 tone burst와 click sound의 네 가지 자극음을 $100 \mathrm{~dB} \mathrm{nHL}$ 강도로 주었다. cVEMP의 측 정은 피검자가 방음실에서 편하게 누운 자세에서 실시하였 고 고개를 검사 측의 반대편으로 돌린 후 일정한 힘을 유지 하도록 한 후 시행하였다. 근전위의 측정은 Auditory evoked potential system, navigation Pro ver. 6.1.0(Bio-logic System Corp., Mundelein, IL, USA)을 사용하였다. p13, n23 사이의 interpeak amplitude을 기록한 후, 양이 간의 진폭의 상대적 차이를 확인하여 IAD ratio를 계산하였다. 그리고 계산된 IAD ratio를 이용하여 $95 \%$ 유의수준으로 각 조건별 cVEMP의 정 상 상한치를 구하였다. 측정된 파형은 rectification 과정을 진 행하였고, rectification을 시행하기 전과 동일하게 IAD ratio 및 정상 상한치를 구하였다.

IAD $\operatorname{ratio}(\%)=100 \times[$ Amplitude(left)-Amplitude(right)]/ [Amplitude(left)+Amplitude(right)]

정상 상한치 $(\%)=$ Mean value of IAD ratio $+2 \times$ Standard deviation of IAD ratio

\section{통계학적 분석}

통계학적 처리는 SPSS 13.0(SPSS software, SPSS Inc., Chicago, IL, USA)을 이용하였으며, 각 조건에 따라 IAD ratio 의 차이를 확인하기 위해 Wilcoxon Signed Ranks검사를 시 행하였으며 $p$-value $<0.05$ 를 기준으로 유효성을 판정하였다.

\section{결 과}

모든 피검자에서 각 조건별 $\mathrm{p} 13, \mathrm{n} 23$ 파형을 얻을 수 있었으 며 interpeak amplitude를 구하였다. 각 조건에서 평균 inter-

Table 1. Comparison of non-rectified cVEMP amplitude values for four different sound stimulus from five locations on SCM muscle

\begin{tabular}{lccccc}
\hline & Site 1 & Site 2 & Site 3 & Site 4 & Site 5 \\
\hline $500 \mathrm{~Hz}(\mathrm{mV})$ & $147.7 \pm 83.1$ & $405.4 \pm 226.9$ & $436.0 \pm 219.5$ & $201.5 \pm 116.7$ & $274.2 \pm 169.5$ \\
$1000 \mathrm{~Hz}(\mathrm{mV})$ & $106.6 \pm 59.9$ & $200.5 \pm 111.9$ & $194.7 \pm 80.5$ & $116.8 \pm 60.3$ & $155.2 \pm 97.2$ \\
$2000 \mathrm{~Hz}(\mathrm{mV})$ & $95.0 \pm 48.9$ & $158.9 \pm 85.1$ & $187.6 \pm 94.3$ & $93.8 \pm 42.2$ & $107.5 \pm 56.1$ \\
Click $(\mathrm{mV})$ & $79.6 \pm 41.0$ & $142.7 \pm 91.0$ & $178.8 \pm 107.4$ & $106.0 \pm 50.9$ & $121.4 \pm 81.1$ \\
\hline
\end{tabular}

Electrode locations were: (1) the upper part of the SCM at the level of mandibular angle, (2) the center between site (1) and site (3), (3) the classical electrode site, (4) the center of sternum division of the SCM, (5) the center of clavicle division of the SCM. SCM: sternocleidomastoeid, cVEMP: cervical vestibular evoked myogenic potential 
peak amplitude 값을 비교하였을 때 표면 전극은 기존 검사 시 부착부위(site 3)에 부착하고 $500 \mathrm{~Hz}$ 의 자극음을 가하였 을 때 interpeak amplitude은 최대값을 보였다(Table 1). Site $3,500 \mathrm{~Hz}$ 의 자극 조건에서 interpeak amplitude 수치는 기존 부착 부위와 유양돌기의 중앙부위(site 2)에서 $500 \mathrm{~Hz}$ 의 자극 음을 가하는 자극 조건을 제외한 모든 자극 조건에서의 interpeak amplitude와 통계적으로 유의한 차이를 보였다 $(p>0.05)$.

Rectification 과정을 하지 않았을 때에 IAD ratio는 500 $\mathrm{Hz}$ 의 자극음을 주었을 때 site 1 에서 $23.1 \pm 18.8 \%$, site 2 에서 $24.1 \pm 12.4 \%$, site 3 에서 $20.8 \pm 14.2 \%$, site 4 에서 $22.0 \pm 14.3 \%$, site 5 에서 $30.8 \pm 20.4 \%$ 이며, $1000 \mathrm{~Hz}$ 의 자극음을 주었을 때 site 1 에서 $30.0 \pm 14.2 \%$, site 2 에서 $27.9 \pm 18.2 \%$, site 3 에서 $19.3 \pm 14.6 \%$, site 4 에서 $26.4 \pm 19.1 \%$, site 5 에서 $26.3 \pm 15.7 \%$ 이며, $2000 \mathrm{~Hz}$ 의 자극음을 주었을 때 site 1 에서 $22.2 \pm 19.8 \%$, site 2 에서 $20.4 \pm 17.4 \%$, site 3 에서 $18.7 \pm 14.3 \%$, site 4 에서 22.1 $\pm 12.9 \%$, site 5 에서 $27.4 \pm 26.2 \%$ 이며, click sound를 자극음 으로 주었을 때 site 1 에서 $26.2 \pm 17.3 \%$, site 2에서 $47.2 \pm 30.0 \%$, site 3 에서 $30.6 \pm 11.2 \%$, site 4 에서 $26.0 \pm 24.6 \%$, site 5 에서 20.8 $\pm 19.5 \%$ 였다(Fig. 2). 기존 조건인 $500 \mathrm{~Hz}$, site 3에서 수 치와 가장 작은 수치를 보인 $2000 \mathrm{~Hz}$, site 3에서의 수치를 비 교 하였을 때에 유의한 차이는 보이지 않았다 $(p>0.05)$.

Rectification 과정을 시행한 후의 IAD ratio는 $500 \mathrm{~Hz}$ 의
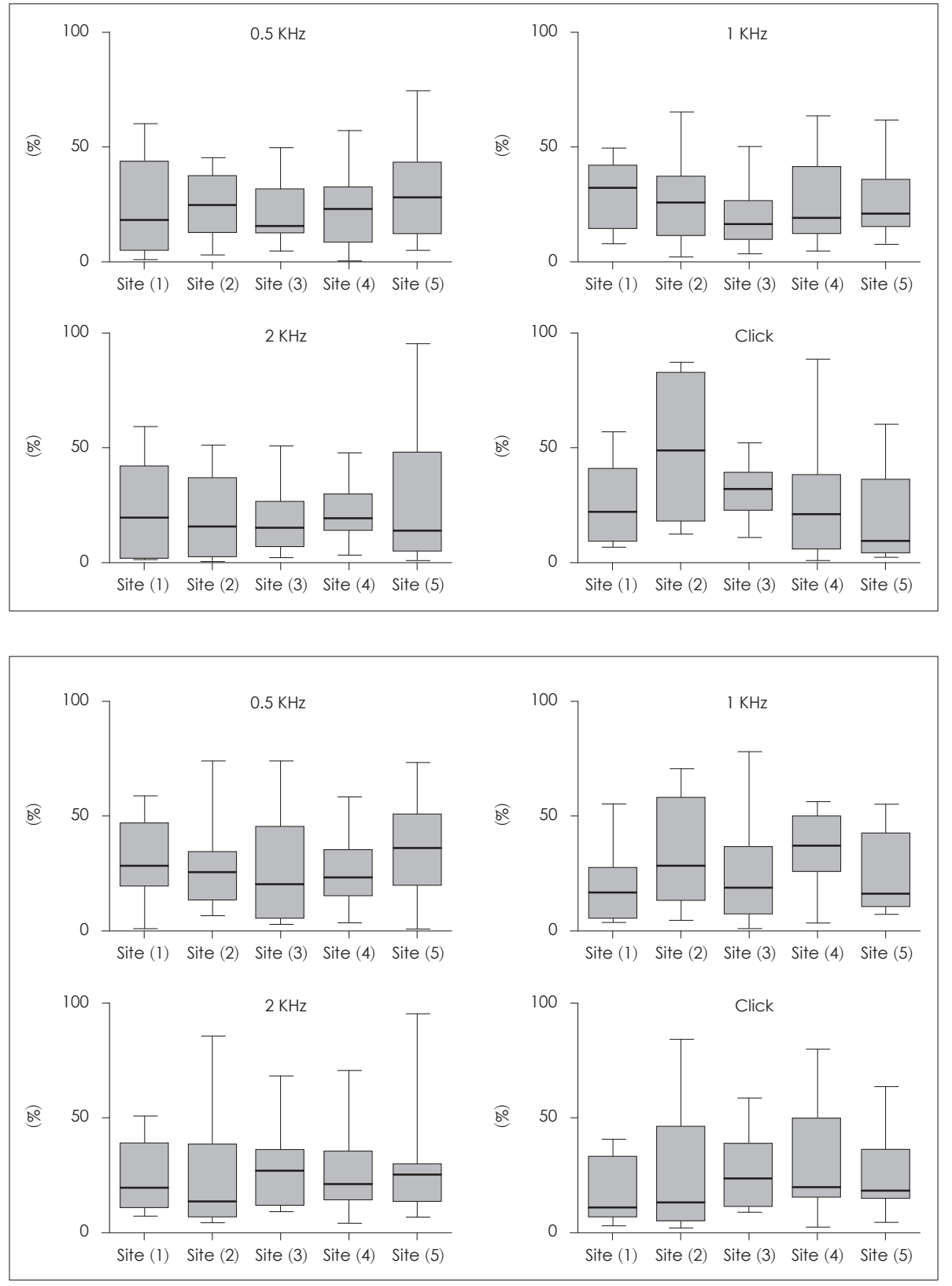

Fig. 2. Mean interaural amplitude in each test condition using five different electrode locations when elicited by four sound stimuli. Electrode locations were: (1) the upper part of the SCM at the level of mandibular angle, (2) the center between site (1) and site (2), (3) the classical electrode site, (4) the center of sternum division of the SCM, (5) the center of clavicle division of the SCM. SCM: sternocleidomastoeid.
Fig. 3. Mean rectified interaural amplitude difference in each test condition using five different electrode locations when elicited by four sound stimulus. Electrode locations were: (1) the upper part of the SCM at the level of mandibular angle, (2) the center between site (1) and site (2), (3) the classical electrode site, (4) the center of sternum division of the $\mathrm{SCM},(5)$ the center of clavicle division of the SCM. SCM: sternocleidomastoeid. 
Table 2. Upper normal value of IAD (\%): when used the unrectified IAD data

\begin{tabular}{lccccc}
\hline & Site 1 & Site 2 & Site 3 & Site 4 & Site 5 \\
\hline $500 \mathrm{~Hz}$ & 48 & 42 & 39 & 39 & 60 \\
$1000 \mathrm{~Hz}$ & 53 & 46 & 33 & 51 & 48 \\
$2000 \mathrm{~Hz}$ & 51 & 44 & 31 & 37 & 56 \\
Click & 48 & 97 & 47 & 44 & 44 \\
\hline
\end{tabular}

Electrode locations were: (1) the upper part of the SCM at the level of mandibular angle, (2) the center between site (1) and site (3), (3) the classical electrode site, (4) the center of sternum division of the SCM, (5) the center of clavicle division of the SCM. IAD: interaural amplitude difference, SCM: sternocleidomastoeid

Table 3. Upper normal value of IAD (\%): when used the rectified IAD data

\begin{tabular}{lccccc}
\hline & Site 1 & Site 2 & Site 3 & Site 4 & Site 5 \\
\hline $500 \mathrm{~Hz}$ & 56 & 41 & 49 & 41 & 63 \\
$1000 \mathrm{~Hz}$ & 32 & 66 & 48 & 59 & 48 \\
$2000 \mathrm{~Hz}$ & 43 & 46 & 44 & 51 & 38 \\
Click & 38 & 50 & 46 & 65 & 52 \\
\hline
\end{tabular}

Electrode locations were: (1) the upper part of the SCM at the level of mandibular angle, (2) the center between site (1) and site (3), (3) the classical electrode site, (4) the center of sternum division of the SCM, (5) the center of clavicle division of the SCM. SCM: sternocleidomastoeid, IAD: interaural amplitude difference

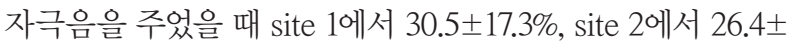
$16.7 \%$, site 3 에서 $26.4 \pm 22.3 \%$, site 4 에서 $25.0 \pm 15.6 \%$, site 5 에서 $35.1 \pm 19.1 \%$ 이며, $1000 \mathrm{~Hz}$ 의 자극음을 주었을 때 site 1 에서 $18.1 \pm 14.2 \%$, site 2 에서 $33.2 \pm 23.0 \%$, site 3 에서 $25.8 \pm$ $23.7 \%$, site 4 에서 $35.9 \pm 14.4 \%$, site 5 에서 $23.8 \pm 17.2 \%$ 이며, $2000 \mathrm{~Hz}$ 의 자극음을 주었을 때 site 1 에서 $24.1 \pm 14.3 \%$, site 2 에서 $25.4 \pm 24.5 \%$, site 3 에서 $27.5 \pm 16.2 \%$, site 4 에서 26.4 $\pm 18.1 \%$, site 5 에서 $27.0 \pm 21.0 \%$ 이며, click sound를 자극음 으로 주었을 때 site 1 에서 $17.4 \pm 13.7 \%$, site 2 에서 $17.4 \pm 16.4 \%$, site 3 에서 $27.5 \pm 15.9 \%$, site 4 에서 $31.2 \pm 24.2 \%$, site 5 에서 24.4 $\pm 16.7 \%$ 였다(Fig. 3). 기존 조건인 $500 \mathrm{~Hz}$, site 3에서 수치 와 가장 작은 수치를 보인 click sound, site 1에서의 수치를 비교 하였을 때에 유의한 차이는 보이지 않았다 $(p>0.05)$.

계산된 IAD ratio를 이용하여 각 조건별 $\mathrm{cVEMP}$ 의 정상 상한치를 구했을 때, rectification 과정을 하지 않았을 경우 에는 $2000 \mathrm{~Hz}$ 의 자극음을 주었을 때 site 3에서 $31 \%$ 로 최소 값이였고(Table 2), rectification 과정을 시행한 경우에는 $1000 \mathrm{~Hz}$ 의 자극음을 주었을 때 site 1에서 $32 \%$ 로 최소값이 었다(Table 3).

\section{고 찰}

인간의 전정계의 구성을 크게 나누어 볼 때 말초전정신경 계와 중추전정신경계 그리고 신체의 평형과 안구의 안정성을 유지하는 전정계가 있다. 이 중 전정계의 기능을 평가하는 방법들 중 많이 이용되는 온도안진 검사 및 회진검사는 주로 수평반고리관의 자극에 의한 전정안반사를 유도하며 그로 인해 발생한 안구의 운동을 측정하는 방법이다. 그러나 이석
기관의 자극에 의한 반응과 전정척수 반사를 이용하여 전정계 의 기능을 평가하는 검사는 cVEMP만이 널리 이용되고 있다.

임상적으로 $\mathrm{cVEMP}$ 가 활용되는 예는 일측의 구형낭 또는 하전정신경의 기능의 저하를 야기할 수 있는 전정신경염이나 메니에르병과 같은 질환이 있는 경우에 환측의 cVEMP의 interpeak amplitude 값이 작아지게 되며 그에 따라 높아진 IAD ratio가 일정 기준 이상일 때 병적인 상태로 확인할 수 있으 며, 병의 진단에 유용하게 사용할 수 있다. ${ }^{2}$ 그러나 cVEMP의 interpeak amplitude는 흥쇄유돌근의 수축력에도 영향을 받아 근육의 수축을 강하게 할수록 interpeak amplitude의 크기도 크게 측정이 된다. ${ }^{5}$ 따라서 양측 경부 수축력의 차이 로 인하여 발생한 interpeak amplitude의 차이는 IAD ratio 값이 커지는 결과를 불러오게 되며, 이러한 경우와 실제 전정 기능의 병인에 의한 경우를 구분하기 어렵기 때문에 결과의 해석에 있어 위양성을 줄이기 위하여 $\mathrm{cVEMP}$ 의 정상 상한치 가 높아지게 되고 결국 민감도가 감소하게 된다. 이에 cVEMP 의 민감도 및 임상적 활용성을 높일 수 있는 이상적인 조건 을 찾아 보고자 하였다.

$\mathrm{cVEMP}$ 에서 적절한 조건을 찾기 위한 기존의 연구들을 고 찰해보면 Murofushi 등 ${ }^{4}$ 은 click sound보다 STB를 이용할 때 interpeak amplitude가 더 큰 값을 가지게 되며 따라서 $\mathrm{STB}$ 가 cVEMP 검사에서 더 적절한 자극음이라고 하였으며, Sheykholeslami 등 ${ }^{3}$ 은 cVEMP 검사에서 STB를 자극음으 로 사용할 때 표면 전극의 위치를 흥쇄유돌근의 상부, 중앙, 쇄골분지, 흥골분지에 부착하였을 때 interpeak amplitude의 크기와 분포에 대한 연구에서 흥쇄유돌근의 상부와 중앙에 서 interpeak amplitude가 충분히 큰 값을 가지며 상부에서 측정된 평균 수치가 중앙에서의 측정 평균 수치에 비해 큰 수 
치지만 중앙에서 측정된 수치가 더 일정한 값을 가지며, 좁은 분포를 보이기 때문에 cVEMP 검사시에 중앙 부위가 더 이상 적인 측정 부위라고 하였다. 이러한 연구들에 기초하여 현재 cVEMP 검사시에는 $500 \mathrm{~Hz}$, STB 자극음을 사용하며 표면 전극은 흉쇄유돌근의 중앙부위에 부착하는 조건을 널리 이 용하고 있다. 그러나 이 조건은 interpeak amplitude가 가장 높게 나타나는 조건으로 $\mathrm{cVEMP}$ 에서 임상적으로 주로 확인 하는 지표인 IAD ratio가 정상인에서 좌우 차이를 가장 작게 나타나는 따라서 $\mathrm{IAD}$ 의 정상 상한치를 최소화할 수 있는 적 절한 조건은 아니다. 따라서 본 연구에서는 interpeak amplitude 크기보다는 IAD ratio와 이를 통해 구할 수 있는 cVEMP 의 정상 상한치에 중점을 두어 다양한 조건에 대해 검사를 시행하였다.

표면 전극의 위치에 따라 비교해 보았을 때 site 2 와 site 3 에 서 다른 부위에 표면 전극이 위치할 때보다 큰 interpeak amplitude 수치를 보였으며 자극음에 따른 비교에는 $500 \mathrm{~Hz}$ 의 자극음에서 다른 자극음에 비해 큰 interpeak amplitude 수 치를 나타냈다. 특히 site 3의 표면 전극에서 $500 \mathrm{~Hz}$ 의 자극음 을 가하였을 때 가장 큰 interpeak amplitude 수치를 보였다. 이러한 결과는 앞에서 언급했던 다양한 조건에 따른 interpeak amplitude의 크기와 적절성에 대해 보고를 했던 Murofushi와 Sheykholeslami의 연구 결과와 일치하는 점으로 본 연구에 서 각 조건을 설정함에 있어 표면 전극의 위치와 자극음이 적절하게 설정되었음을 뜻한다 하겠다.

$\mathrm{cVEMP}$ 검사에서 임상에서 주로 활용되는 지표인 파형의 존재 유무와 IAD ratio는 본 연구에서는 13명, 26귀에서 모두 반응을 얻을 수 있었다. 이는 노인이나 급성 전정 기능 저하를 일으킬 수 있는 병력을 가진 자는 반응이 나타나지 않을 가능 성이 있기 때문에 연구에 포함시키지 않았기 때문이라고 생각 한다. 조건별로 비교하였을 때에 rectification을 하지 않았을 경우 IAD ratio의 평균 값은 최소 $18.7 \%$ 에서 최대 $30.0 \%$ 였으 며, rectification을 하였을 경우 IAD ratio의 평균 값은 최소 $17.4 \%$ 에서 최대 $35.1 \%$ 를 보였다. 근육의 피로를 느끼지 않게 피험자들은 검사 사이에 적어도 5 분 이상의 충분한 휴식시 간을 가졌다. 그리고 모든 피험자들이 젊고 건강한 자들이였 으며 협조가 잘 이루어졌으며 실험자는 근전도 평균정류전 압을 200 400 mV로 근육 수축 정도를 정량화하여 모니터 링을 하였기 때문에 양측의 근육 수축력의 차이가 최소화 될 수 있었을 것으로 생각한다. 대부분의 조건에서 rectification 을 시행한 후 IAD ratio가 커지는 경향을 보였는데, 양측 근 육의 수축력이 비슷한 조건에서는 rectification의 이점이 없 어진다는 기존의 연구 결과에 비추어 설명이 가능하다고 생 각한다. $\operatorname{Kim}$ 등 ${ }^{6}$ 은 근육 수축력의 차이가 $22.5 \%$ 이하의 작은
차이를 보일 경우에는 rectification 과정이 반드시 필요한 것 은 아니며 IAD ratio도 rectification 과정을 거치지 않았을 경 우와 큰 차이를 보이지 않을 수 있다 하였다. 그러나 이러한 수치는 매 검사시에 공통적으로 적용할 수 있는 수치는 아니 며, 각 피험자 별로 근육 수축력의 차이가 얼마나 차이를 보 일지 실험 전에 예측할 수 없기 때문에 모든 경우에 rectification은 필요하다 생각된다.

여러 보고에 따르면, $\mathrm{cVEMP}$ 검사에서 IAD ratio의 정상 상 한치는 34.1 60.4\%로 보고된다. ${ }^{7-14)}$ 임상에서 널리 쓰이는 조 건인 $500 \mathrm{~Hz}$, site 3에서 이런한 연구들은 시행되었으며 본 연 구에서 상기 조건하에 정상 상한치는 rectification 과정을 하 지 않았을 경우 $39 \%$ 였다. 그러나 다양한 조건들에서 이보다 더 작은 값을 가지는 조건들을 본 연구에서 확인하였으며 기 존의 조건에 비하여 rectification 과정을 하지 않은 경우 $8 \%$, rectification 과정을 한 후에는 $17 \%$ 의 더 작은 값을 가지는 조건도 있었다. 이는 자극 조건의 변화를 통하여 cVEMP 검 사의 정상 상한치를 낮추고 검사의 신뢰도와 활용성을 높일 수 있다고 생각한다. 따라서 본 연구에서 시사하는 바를 기 초로 실험 대상자를 늘리고 실제 환자들을 대조군으로 하는 $\mathrm{cVEMP}$ 검사의 정상 상한치에 대한 추가적인 연구가 필요하다.

임상에서는 환자의 연령, 근육의 위축, 중이의 상태 등의 요 인으로 인하여 의미 있는 interpeak amplitude를 확인하기 힘 든 경우가 있다. 현재 널리 이용되는 $500 \mathrm{~Hz}, \mathrm{STB}$ 자극음은 앞에서 기술한 바와 같이 interpeak amplitude가 최대값을 보 이는 자극음으로 알려져 있으며 $500 \mathrm{~Hz}, \mathrm{STB}$ 자극음의 이 러한 특성은 간과해서는 안되는 중요한 장점이라 생각된다. $\mathrm{cVEMP}$ 검사에서 이상적인 자극 조건은 interpeak amplitude 가 최대값을 보이며 동시에 IAD ratio를 최소화 시키는 자극 조건이지만 두 기준을 동시에 완벽하게 충족하기에는 한계가 있으며 interpeak amplitude와 IAD ratio가 적정 기준 이상을 만족하는 자극 조건을 찾을 필요가 있다.

본 연구에서 연구한 자극음, 주파수, 표면전극의 위치뿐 아 니라 cVEMP 검사에 영향을 줄 수 있는 변수는 많이 있다. 예 를 들면 흥쇄유돌근의 수축력의 차이, 피부와 전극 사이의 저항, 환자의 자세와 두부의 위치 등이 있으며 동일한 사람에 서도 반복적인 검사시에 결과값이 달라질 수 있다. Park 등 15$)$ 은 혈압계를 이용하여 흥쇄유돌근의 수축력을 정량화 시켜 $20 \mathrm{~mm} \mathrm{Hg}, 40 \mathrm{~mm} \mathrm{Hg}, 60 \mathrm{~mm} \mathrm{Hg}$ 의 압력에서 $95 \mathrm{~dB}$, STB 자극음을 주었을 때 IAD ratio는 $30.7 \pm 17.8 \%, 20.2 \pm 14.9 \%$, $21.9 \pm 16.8 \%$ 로 $40 \mathrm{~mm} \mathrm{Hg}$ 이상의 압력이 적절하다 하였으며 적정 수준 이상의 근 수축이 필요하다 하겠다. 환자의 자세 와 두부의 위치는 크게 두 가지로 나눌 수 있다. 첫째는 본 연구에서 시행한 앉거나 누운 상태에서 머리만 돌리는 자세 
가 있다. 둘째는 경부 근육에 추가적인 하중을 부과하여 보 다 강한 경부 근육 수측을 유도하는 자세로 추가적인 하중 을 부과하는 방법으로 머리를 침대에서 거상하는 방법이 가 장 많이 사용되며, ${ }^{16)}$ 그 외에 머리를 벽에 기대어 미는 방법, 추를 매다는 방법 등이 존재한다. 첫 번째 방법의 경우 위음 성률이 높고, 진폭이 작아지는 문제점이 있으며, 두 번째 방법 의 경우 경부 근육의 과도한 수축으로 근육에 무리를 줄 수 있고 반대편 검사에 영향을 줄 수 있다. ${ }^{17)}$ 본 연구에서는 이러 한 요인에 대해 연구를 하지는 않았지만 이들 요인과 IAD ratio의 관계에 대한 연구도 필요하다고 생각한다.

본 연구의 제한점으로 환자군과의 비교 분석이 없었다. 그 리고 실험 대상자가 13 명으로 비교적 적은 숫자로 연구를 하 게 되어 표준편차가 커지는 등의 문제가 있었다. 추후에 많은 사람을 대상으로 하며 동시에 환자군과의 비교 분석을 통하 여 본 연구의 임상적 유용성에 대해 다시 확인해볼 수 있을 것으로 생각한다.

\section{REFERENCES}

1) Colebatch JG, Halmagyi GM. Vestibular evoked potentials in human neck muscles before and after unilateral vestibular deafferentation. Neurology 1992;42(8):1635-6.

2) Koo JW. Understanding of vestibular evoked myogenic potential and its clinical applications. Korean J Otolaryngol-Head Neck Surg 2004;47(12):1203-10.

3) Sheykholeslami K, Murofushi T, Kaga K. The effect of sternocleidomastoid electrode location on vestibular evoked myogenic potential. Auris Nasus Larynx 2001;28(1):41-3.

4) Murofushi T, Matsuzaki M, Wu CH. Short tone burst-evoked myogenic potentials on the sternocleidomastoid muscle: are these potentials also of vestibular origin? Arch Otolaryngol Head Neck Surg 1999;125(6):660-4.

5) Ochi K, Ohashi T, Nishino H. Variance of vestibular-evoked myogenic potentials. Laryngoscope 2001;111(3):522-7.

6) Kim KW, Jung JY, Lee JH, Suh MW. Capacity of rectified vestibular evoked myogenic potential in correcting asymmetric muscle contraction power. Clin Exp Otorhinolaryngol 2013;6(4):209-13

7) Murofushi T, Matsuzaki M, Mizuno M. Vestibular evoked myogenic potentials in patients with acoustic neuromas. Arch Otolaryngol Head Neck Surg 1998;124(5):509-12.

8) Young $\mathrm{YH}, \mathrm{Wu} \mathrm{CC}, \mathrm{Wu} \mathrm{CH}$. Augmentation of vestibular evoked myogenic potentials: an indication for distended saccular hydrops. Laryngoscope 2002;112(3):509-12.

9) Hong SM, Cha CI, Byun JY, Yeo SG. The results of vestibular evoked myogenic potential in the patients with central vertigo. Korean J Otolaryngol-Head Neck Surg 2006;49(11):1061-4.

10) Rauch SD, Silveira MB, Zhou G, Kujawa SG, Wall C 3rd, Guinan JJ, et al. Vestibular evoked myogenic potentials versus vestibular test battery in patients with Meniere's disease. Otol Neurotol 2004;25 (6):981-6

11) Welgampola MS, Colebatch JG. Vestibulocollic reflexes: normal values and the effect of age. Clin Neurophysiol 2001;112(11):1971-9.

12) Lee KJ, Kim MS, Son EJ, Lim HJ, Bang JH, Kang JG. The Usefulness of Rectified VEMP. Clin Exp Otorhinolaryngol 2008; 1(3):143-7.

13) Ko I, Hong SK, Jang ES, Lee HJ, Kim HJ. Ocular vestibular evoked myogenic potential in healthy subjects: a comparative study with cervical vestibular evoked myogenic potential. Korean J Otorhinolaryngol-Head Neck Surg 2009;52(12):968-73.

14) Isaradisaikul S, Strong DA, Moushey JM, Gabbard SA, Ackley SR, Jenkins HA. Reliability of vestibular evoked myogenic potentials in healthy subjects. Otol Neurotol 2008;29(4):542-4.

15) Park HJ, Han SH, Shim DB, Shin HA, Lim SG, Ahn JY, et al. Changes of VEMP responses by the strength of SCM muscles contraction and stimulation intensities. Korean J Otorhinolaryngol-Head Neck Surg 2007;50(7):579-83.

16) Welgampola MS, Colebatch JG. Characteristics and clinical applications of vestibular-evoked myogenic potentials. Neurology 2005;64(10):1682-8.

17) Suh MW, Jeong SH, Kim JS. Vestibular evoked myogenic potential: recording methods and clinical application. J Korean Neurol Assoc 2010;28(1):1-12 